\title{
Modulating Ferroelectric Response in Colloidal Semiconductor Nanocrystals through Cation Exchange
}

\author{
Cara E. Bradsher ${ }^{1}$, James R. McBride ${ }^{1-3}$, Janet E. Macdonald ${ }^{1,2}$, Sandra J. Rosenthal ${ }^{1-6 *}$ \\ ${ }^{1}$ Department of Chemistry, Vanderbilt University, VU Station B Box 351822, Nashville, Tennessee, 37235, United \\ States \\ ${ }^{2}$ Vanderbilt Institute for Nanoscale Science and Engineering, Vanderbilt University, VU Station B Box 351822, \\ Nashville, Tennessee, 37235, United States \\ ${ }^{3}$ Department of Interdisciplinary Materials Science, Vanderbilt University, VU Station B Box 351822, Nashville, \\ Tennessee, 37235, United States \\ ${ }^{4-6}$ Department of Pharmacology, Department of Physics and Astronomy, Department of Chemical and Biomolecular \\ Engineering, Vanderbilt University, VU Station B Box 351822, Nashville, Tennessee, 37235, United States
}

\section{TEM/STEM-EDS Characterization of Original CdSSe Nanoparticles}

TEM of the original CdSSe quantum dots shows good monodispersity with an overall size distribution of $3 \mathrm{~nm}+/-0.16$. STEM-EDS mapping and the EDS spectrum in figures S1 and S2 confirms the presence of cadmium as well as both sulfur and selenium in the original nanoparticles.

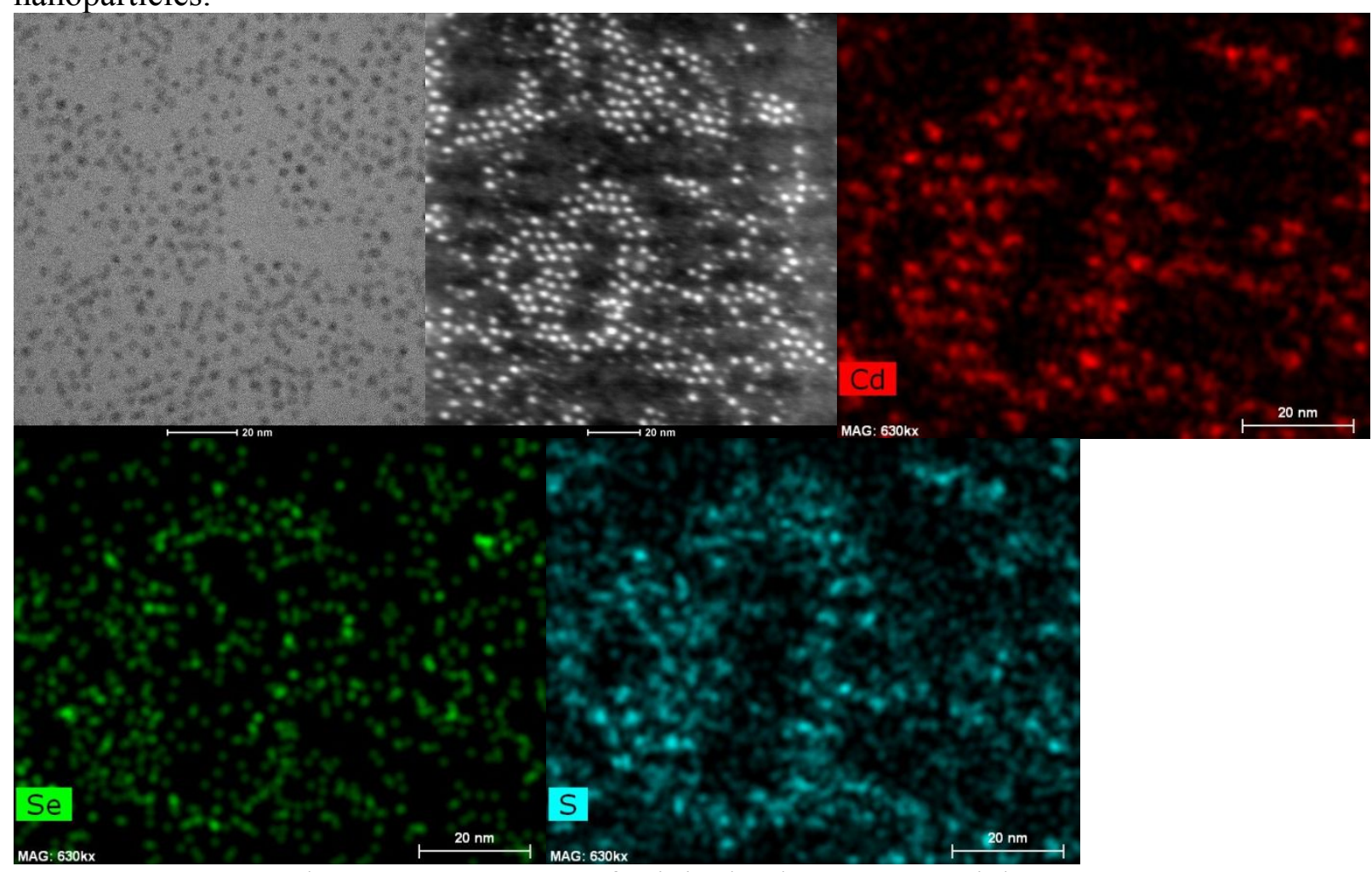

Figure S1. TEM and STEM-EDS maps of original CdSSe nanoparticles. 


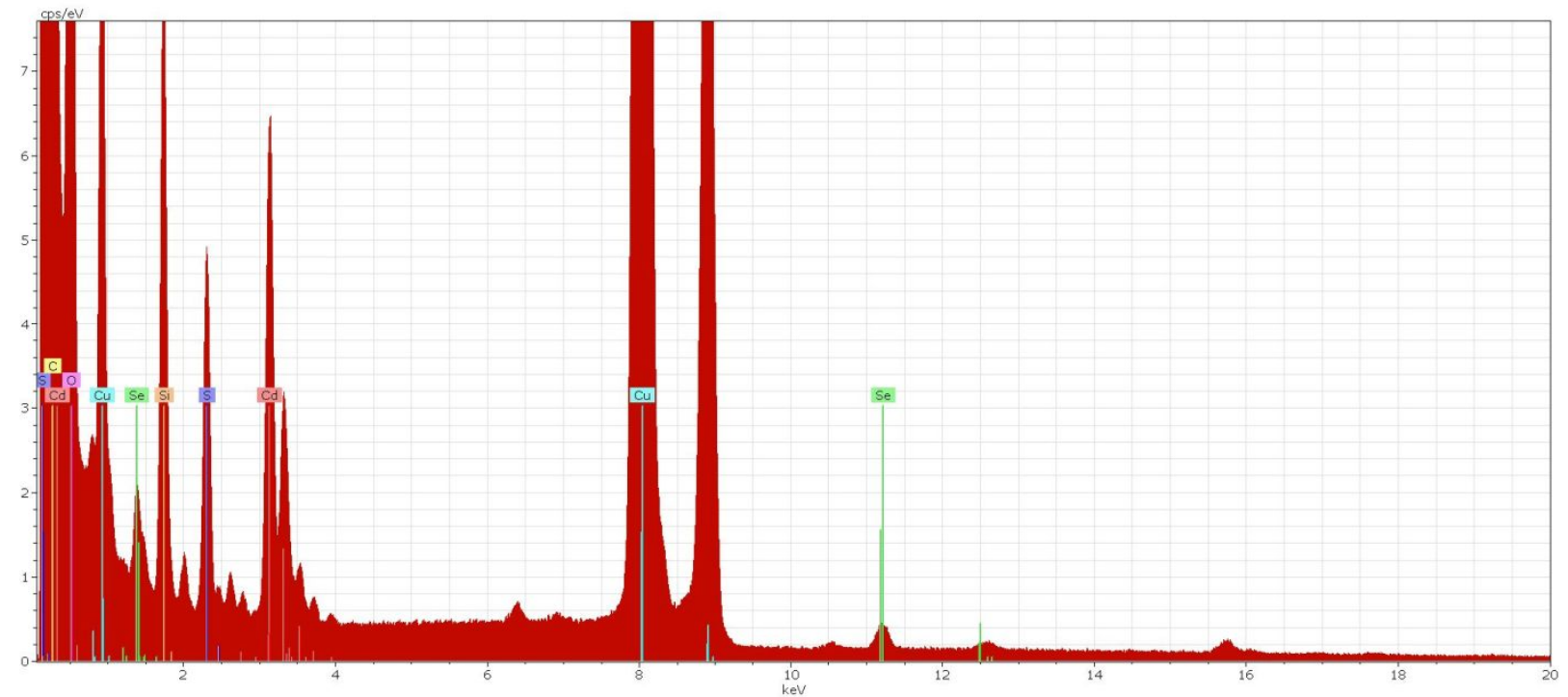

Figure S2. EDS spectrum showing the presence of cadmium, sulfur, and selenium in the original CdSSe nanoparticles.

\section{Clean Cation Exchange.}

In our original synthesis, based upon the previous Wrenn et al. synthesis, the cation exchange was performed with $3 \mathrm{~nm}+/-0.16$ QDs and antimony (III) chloride both dissolved in toluene. The QDs almost immediately crashed out of solution due to a ligand displacement by the chlorine anions while a partial cation exchange occurred between antimony and cadmium. The displaced cadmium reacted with the remaining chlorine anions in solution to form $\mathrm{CdCl}_{2} \cdot \mathrm{H}_{2} \mathrm{O}$, a known ferroelectric. $\mathrm{CdCl}_{2} \cdot \mathrm{H}_{2} \mathrm{O}$ is highly soluble in polar solvents, so in order to remove the byproducts and get more a reliable polarization response, we performed the cation exchange in ethanol rather than toluene to disallow $\mathrm{CdCl}_{2} \cdot \mathrm{H}_{2} \mathrm{O}$ formation completely. TEM and STEM-EDS show large $\mathrm{CdCl}_{2} \cdot \mathrm{H}_{2} \mathrm{O}$ sheets in figures $\mathrm{S} 3$ and $\mathrm{S} 4$ as well as the presence of chlorine on the surface of the QDs due to ligand displacement in the original synthesis in toluene and, while the chlorine is still localized on the QDs, the $\mathrm{CdCl}_{2} \cdot \mathrm{H}_{2} \mathrm{O}$ sheets disappear in the new ethanol synthesis shown in figure S5. This is confirmed through XRD of the original QDs, the synthesis in toluene showing the presence of $\mathrm{CdCl}_{2} \cdot \mathrm{H}_{2} \mathrm{O}$, and the synthesis in ethanol in which the peaks corresponding to $\mathrm{CdCl}_{2} \bullet \mathrm{H}_{2} \mathrm{O}$ disappear shown in figure $\mathrm{S} 6$. 


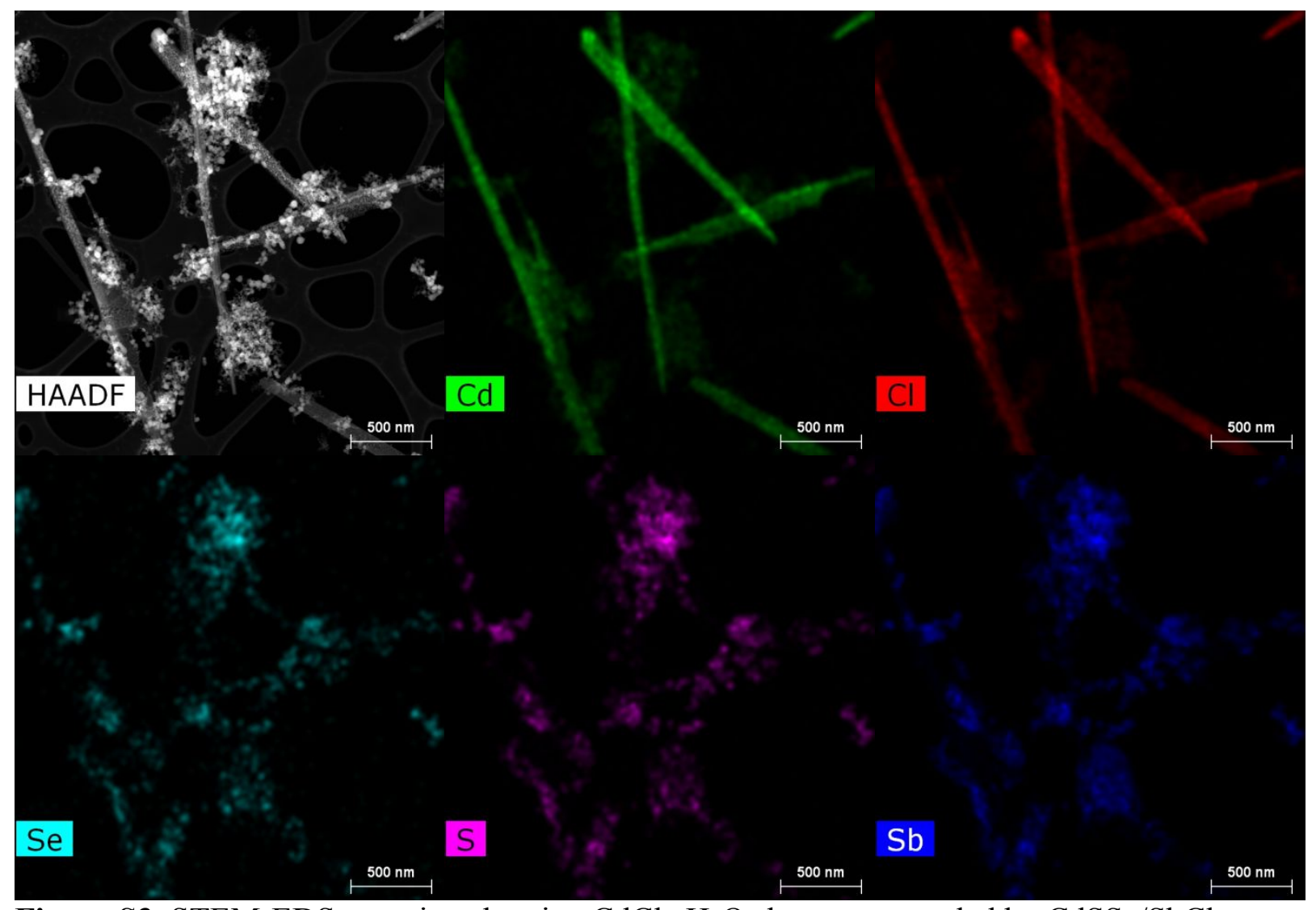

Figure S3. STEM-EDS mapping showing $\mathrm{CdCl}_{2} \cdot \mathrm{H}_{2} \mathrm{O}$ sheets surrounded by $\mathrm{CdSSe} / \mathrm{SbCl}_{3}$ aggregates. $\mathrm{CdCl}_{2} \cdot \mathrm{H}_{2} \mathrm{O}$ forms only in cation synthesis in toluene. 

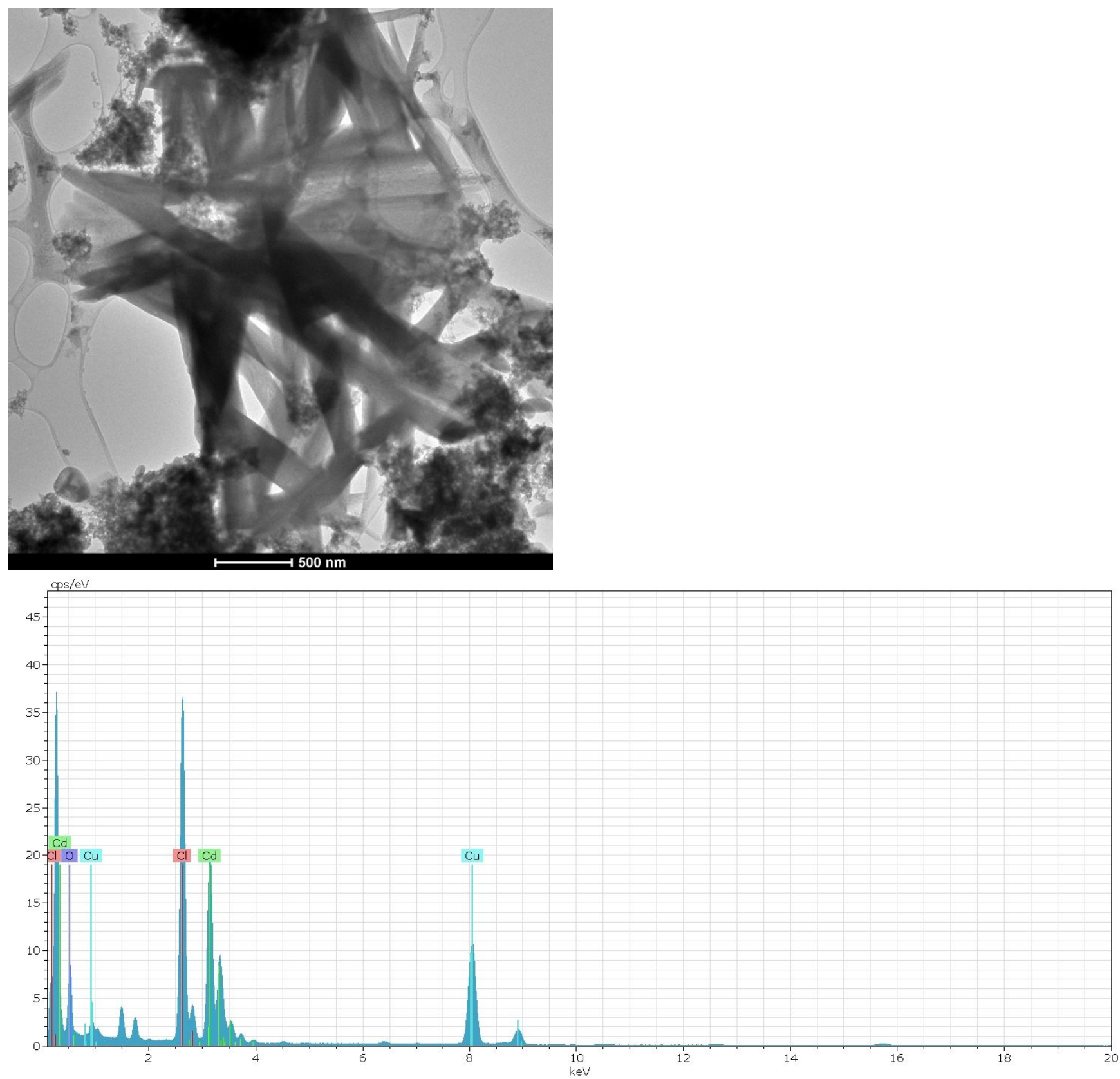

Figure S4. TEM and EDS spectrum of magnified $\mathrm{CdCl}_{2} \bullet \mathrm{H}_{2} \mathrm{O}$ sheets. 


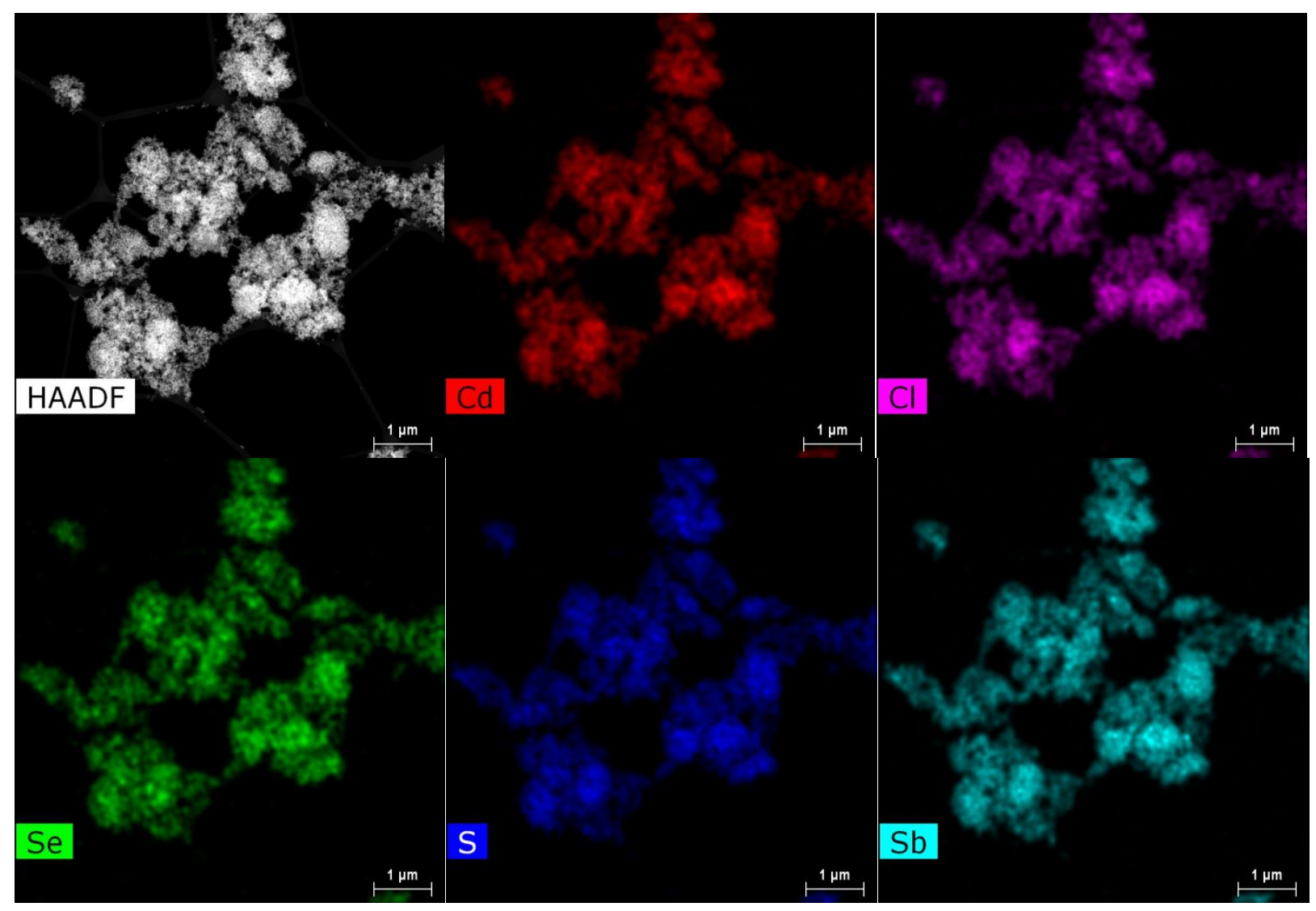

Figure S5. TEM and STEM-EDS of CdSSe/ $\mathrm{SbCl}_{3}$ sans $\mathrm{CdCl}_{2} \cdot \mathrm{H}_{2} \mathrm{O}$. Cation exchange synthesis in ethanol disallows for formation of $\mathrm{CdCl}_{2} \bullet \mathrm{H}_{2} \mathrm{O}$. 


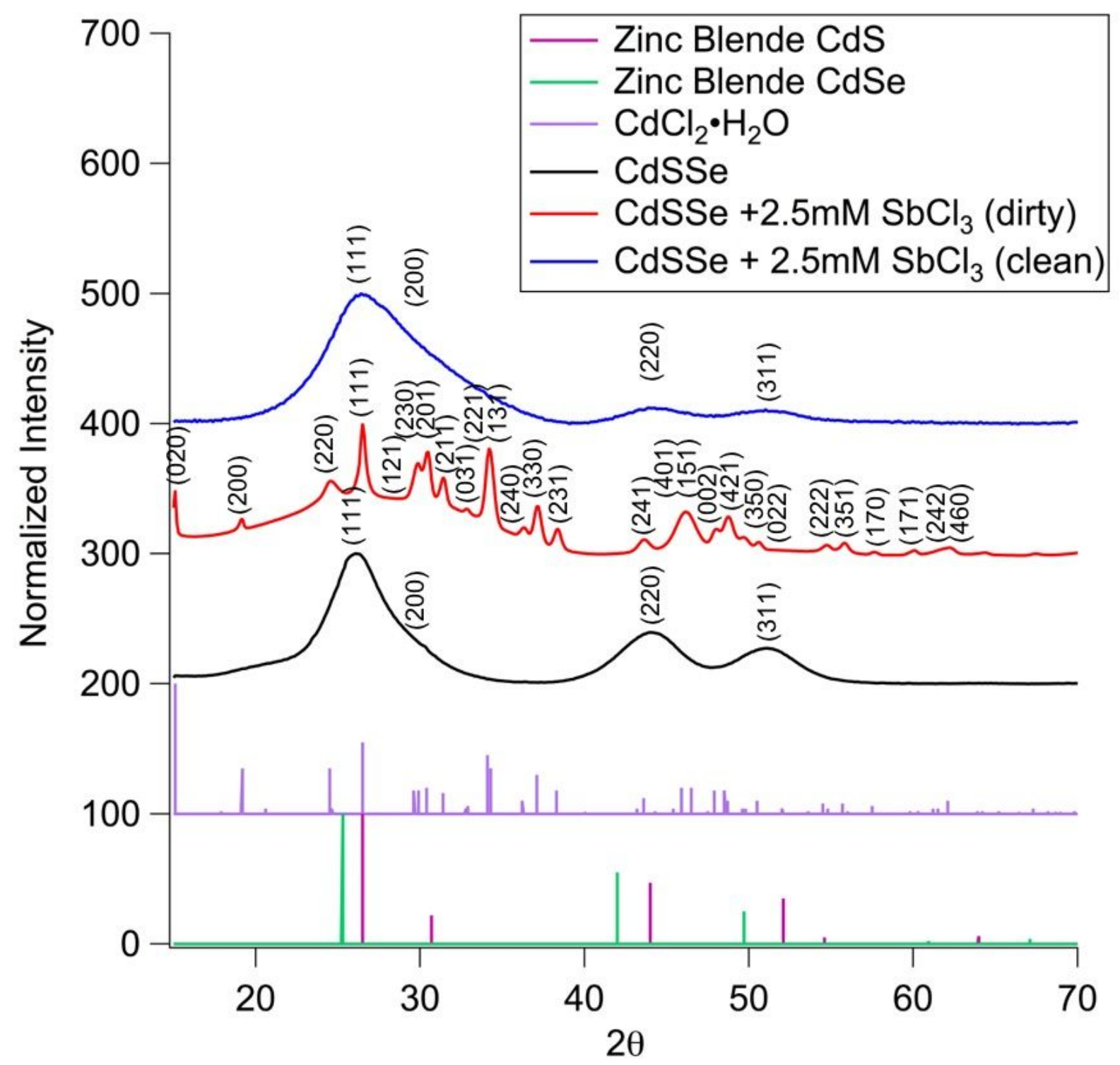

Figure S6. XRD of original $\mathrm{CdSSe}$ quantum dots and $\mathrm{CdSSe} \mathrm{SbCl}_{3}$ cation exchange syntheses in toluene and ethanol to show presence of $\mathrm{CdCl}_{2} \cdot \mathrm{H}_{2} \mathrm{O}$ formation in toluene and that $\mathrm{CdCl}_{2} \cdot \mathrm{H}_{2} \mathrm{O}$ is unable to form in ethanol synthesis.

\section{Effects of Chlorine on Ferroelectric Properties and Ligand Displacement}

Ligand displacement by chlorine anions causes aggregation but has no effects on ferroelectric properties. This has been shown through Sawyer-Tower circuit measurements and STEM-EDS elemental analysis of the cation exchange synthesis using both $\mathrm{NaCl}$, shown in Figure $\mathrm{S} 7$, and $\mathrm{SbI}_{3}$, shown in Figure S8. 


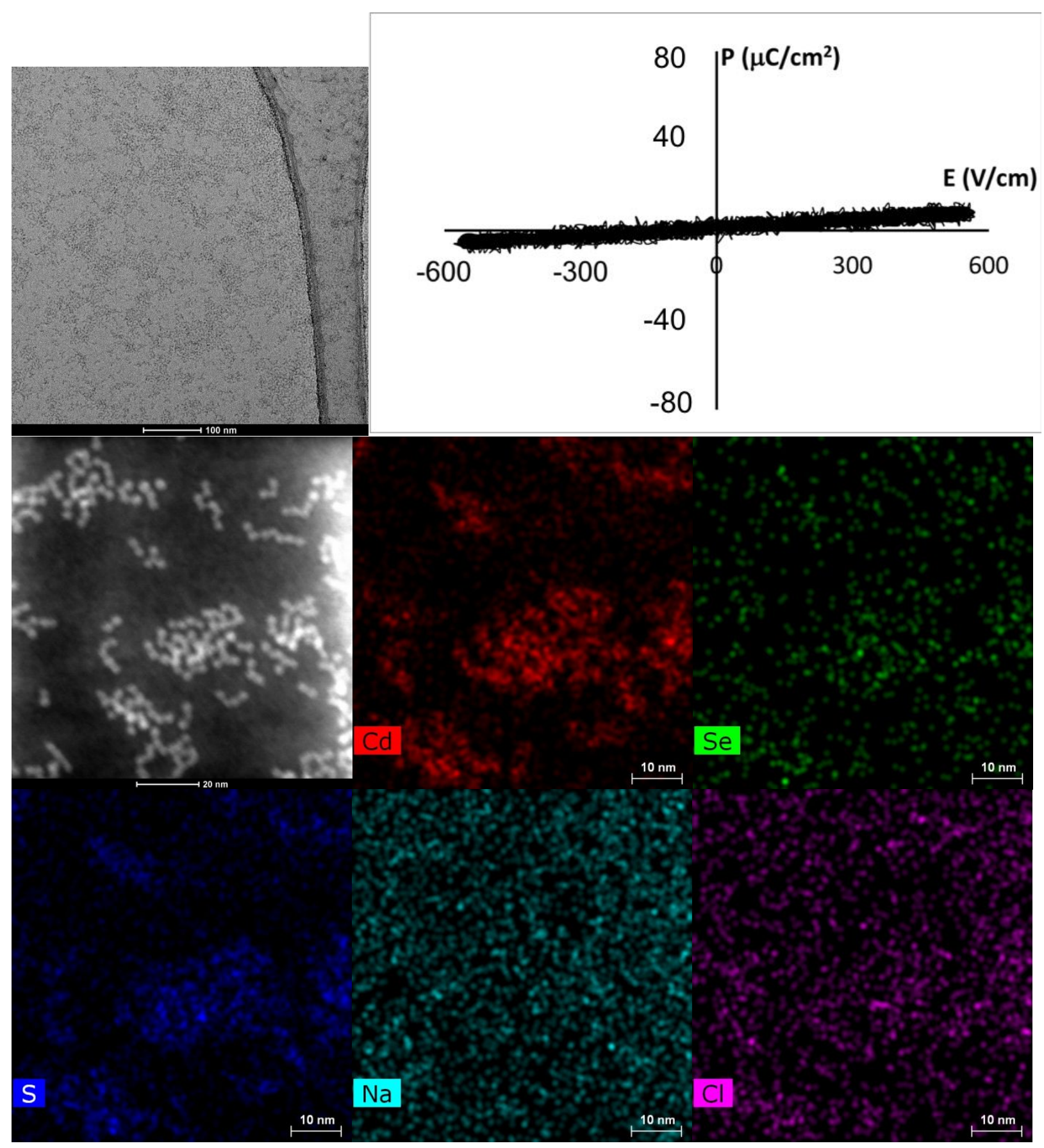




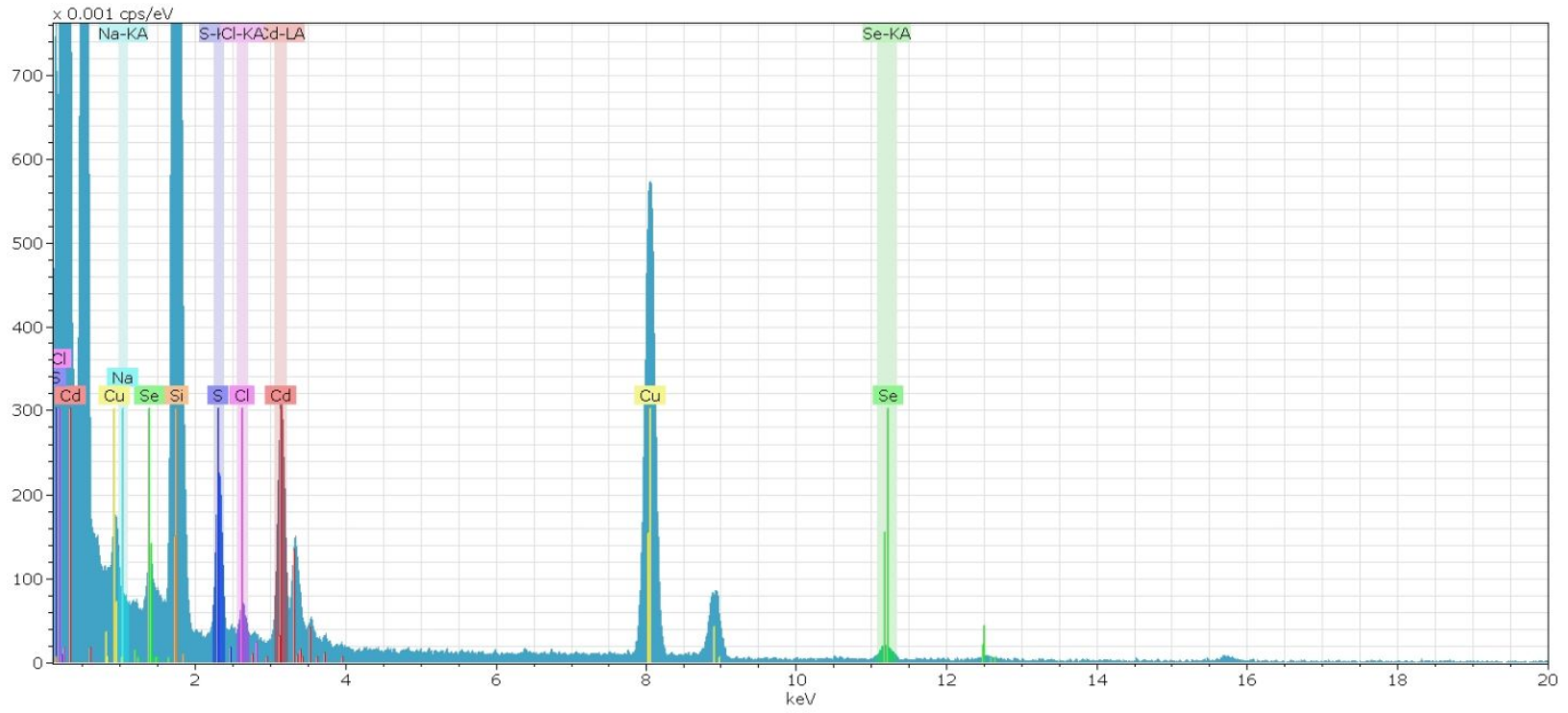

Figure S7. TEM, STEM-EDS mapping, and EDS spectrum when cation exchange synthesis is performed with $\mathrm{NaCl}$ shows that sodium is not present, while aggregation still occurs and due to ligand displacement by chlorine. Sawyer-Tower circuit experiments show no ferroelectric properties. 


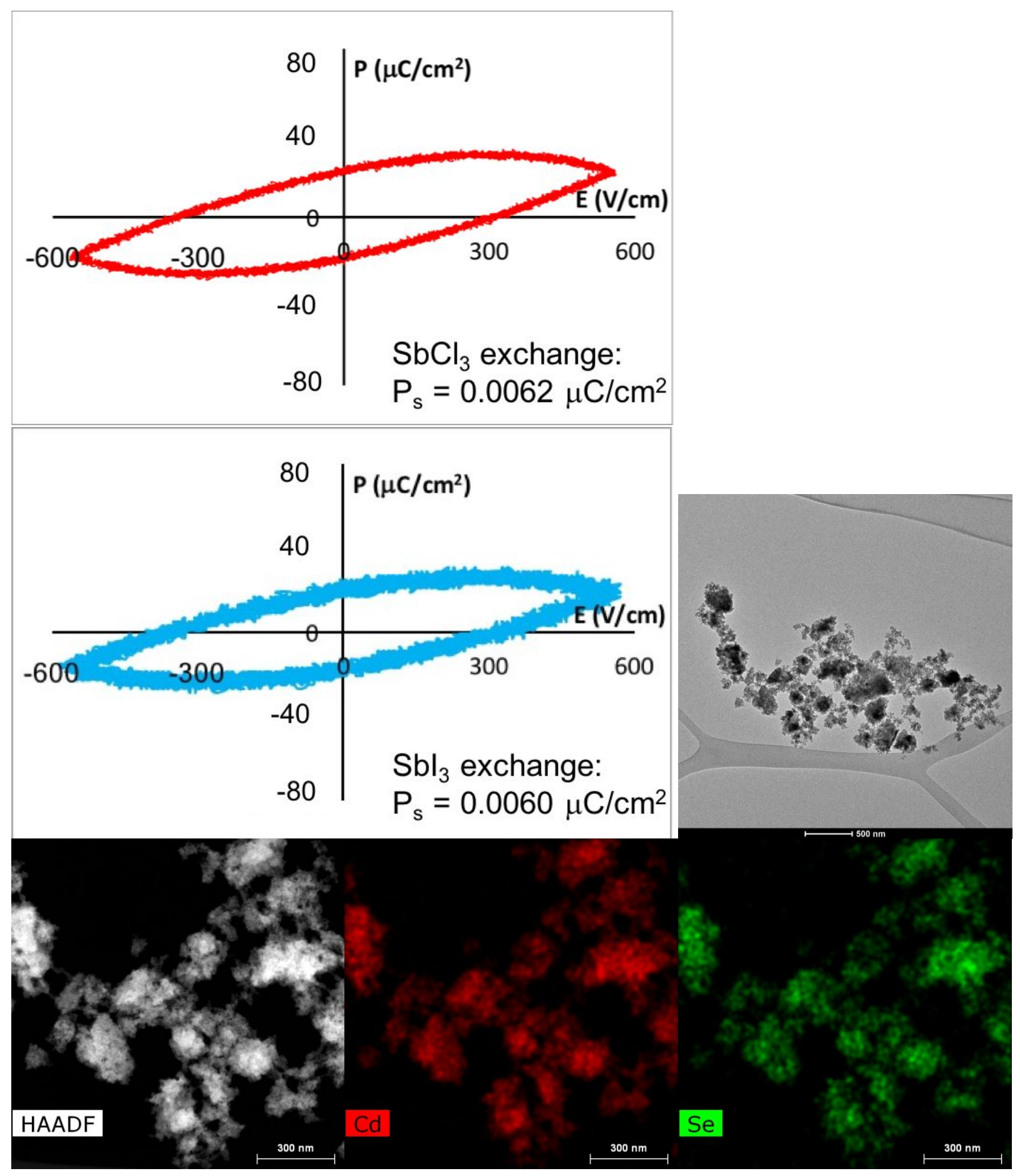



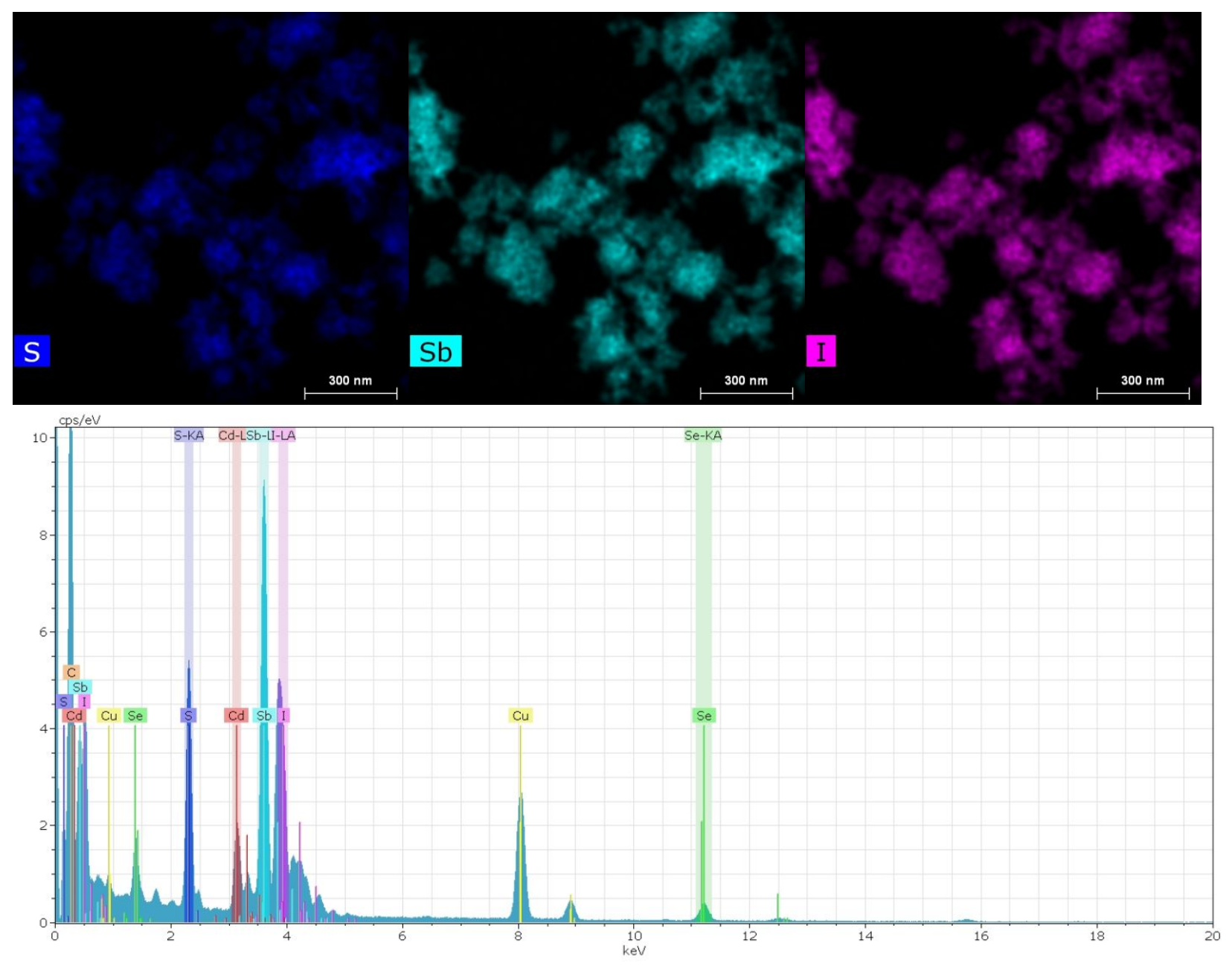

Figure S8. Cation exchange synthesis with both antimony (III) chloride and antimony (III) iodide both result in aggregation and comparable ferroelectric properties. Aggregation is still believed to be due to ligand displacement by iodine shown by STEM-EDS mapping and the EDS spectrum.

\section{Disorder Due to Cation Exchange}

XRD of original CdSSe quantum dots and $\mathrm{CdSSe} / \mathrm{M}^{\mathrm{n}+} \mathrm{Cl}_{\mathrm{n}}$ shows disorder of varying amounts due to cation exchange with every metal chloride salt used in the cation exchange syntheses shown in figure S9. STEM-EDS spectra after each cation exchange are shown in Figure S10. 


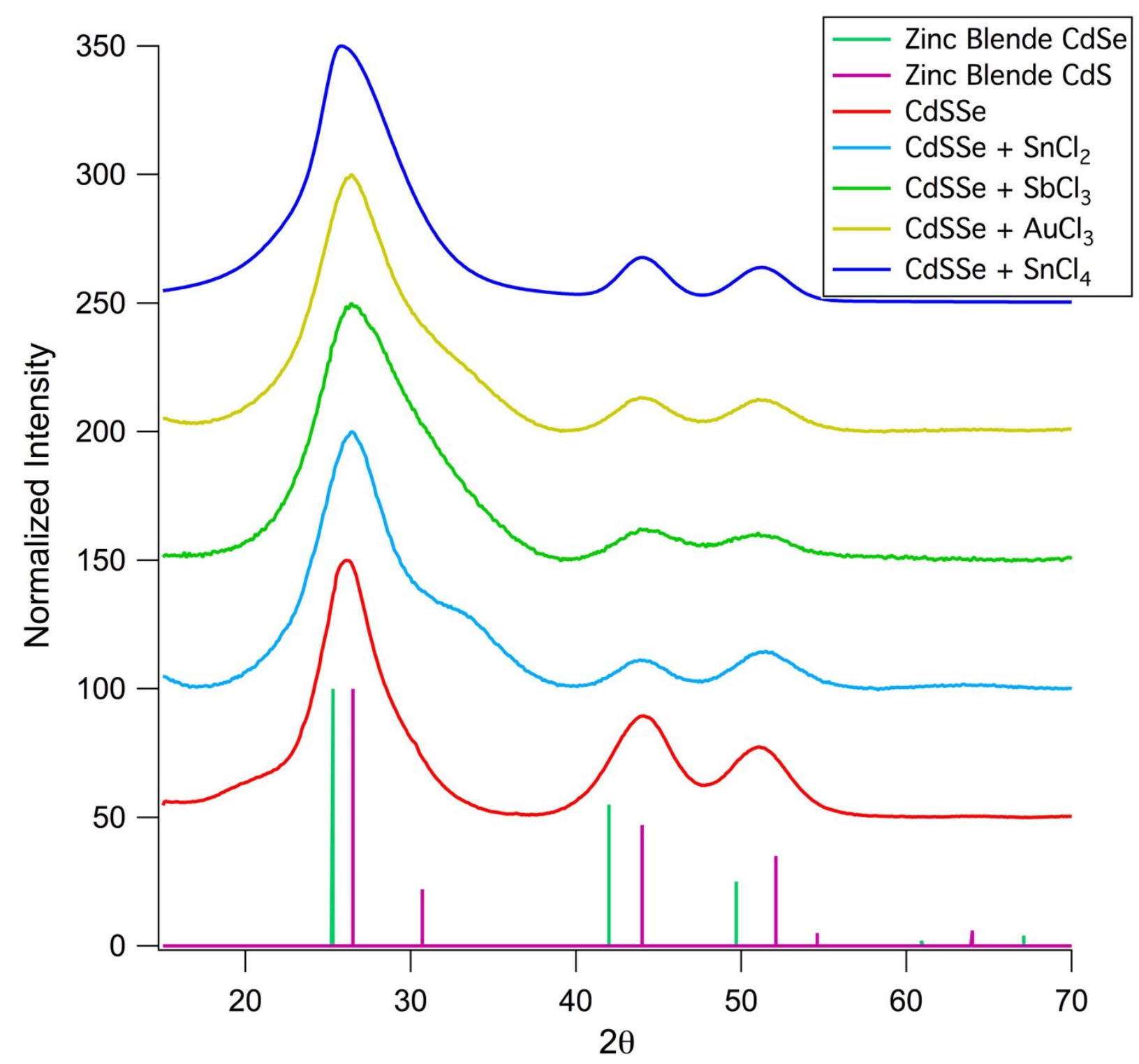

Figure S9. $\mathrm{XRD}$ of CdSSe QDs before and after cation exchange with $\mathrm{SnCl}_{2}, \mathrm{SbCl}_{3}, \mathrm{AuCl}_{3}$, and $\mathrm{SnCl}_{4}$ salts.

\section{Proof of Cation Exchange}

Aggregation occurred with each cation exchange reaction shown through TEM images in figure S10. EDS spectra used in elemental mapping have been quantified to show the presence of the exchange cations at similar ratios with each cation exchange 

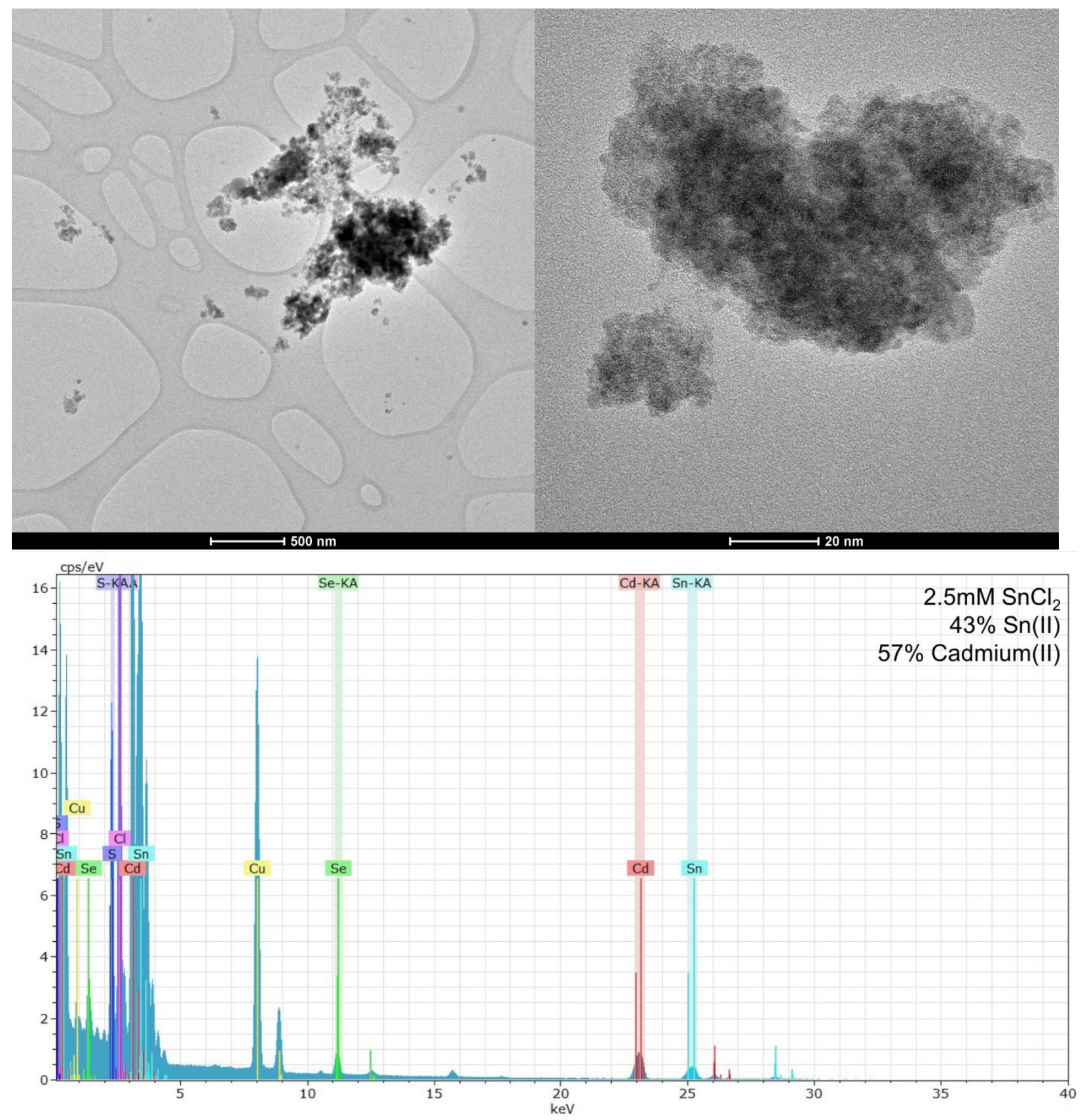

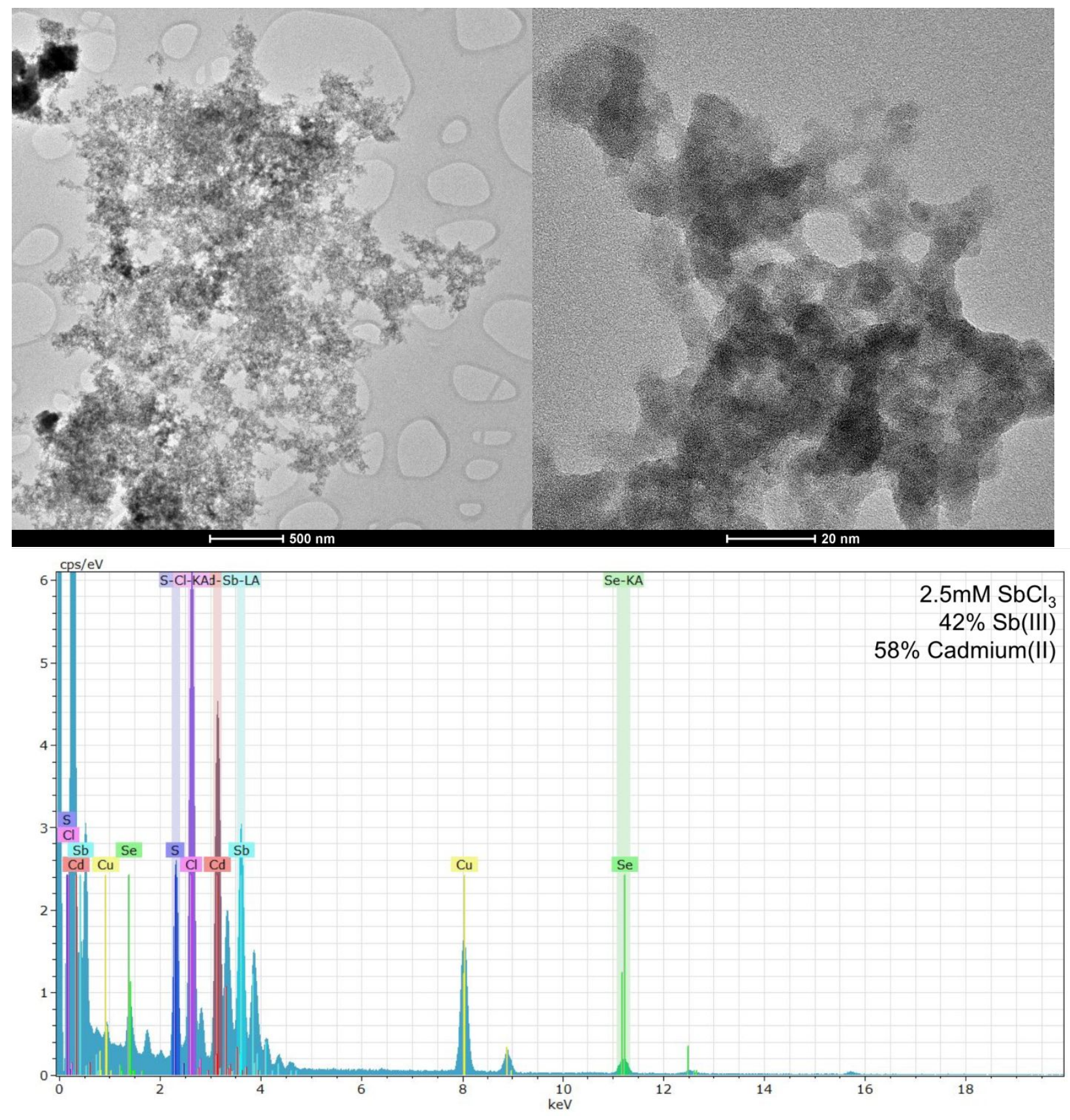

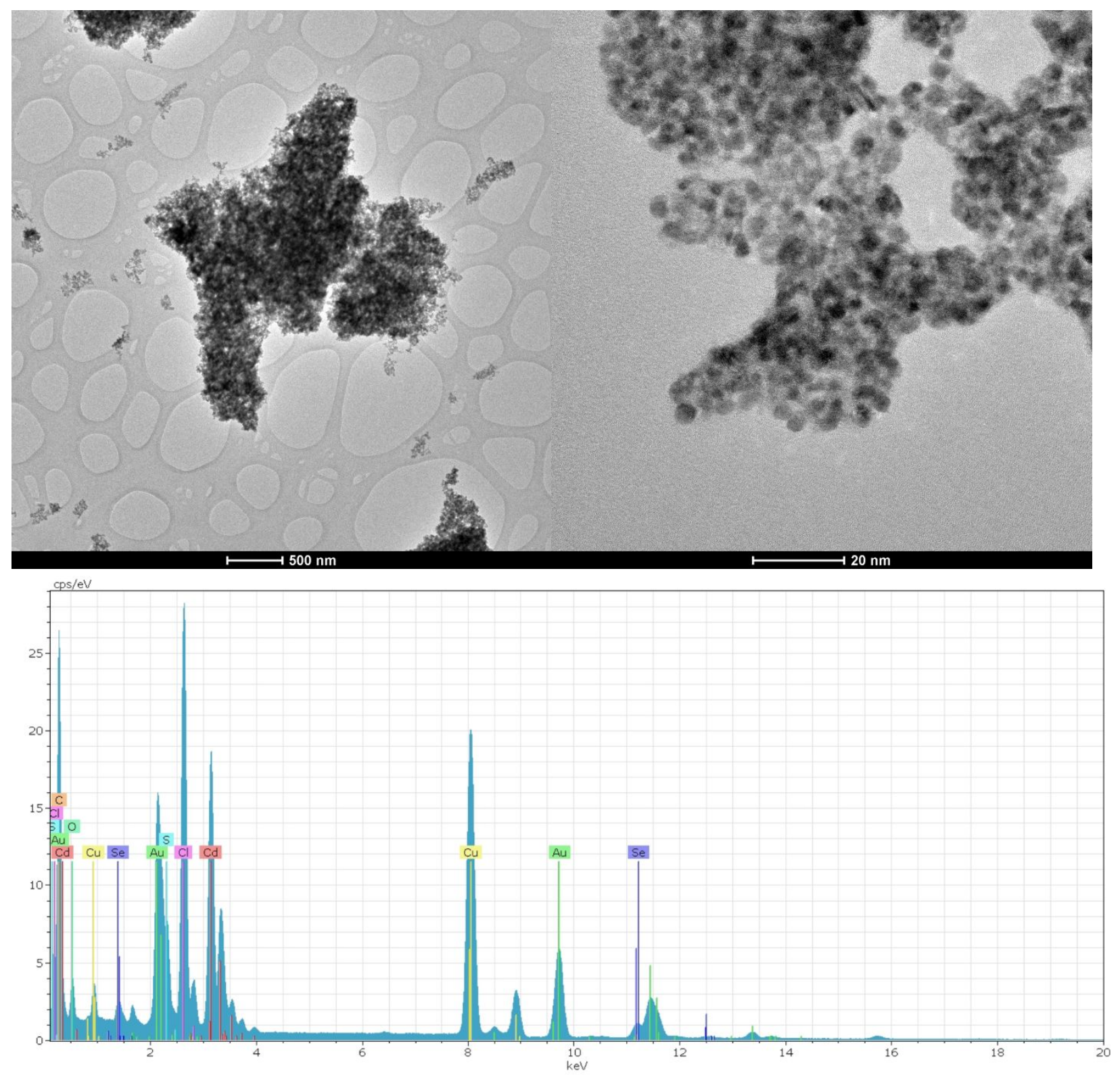

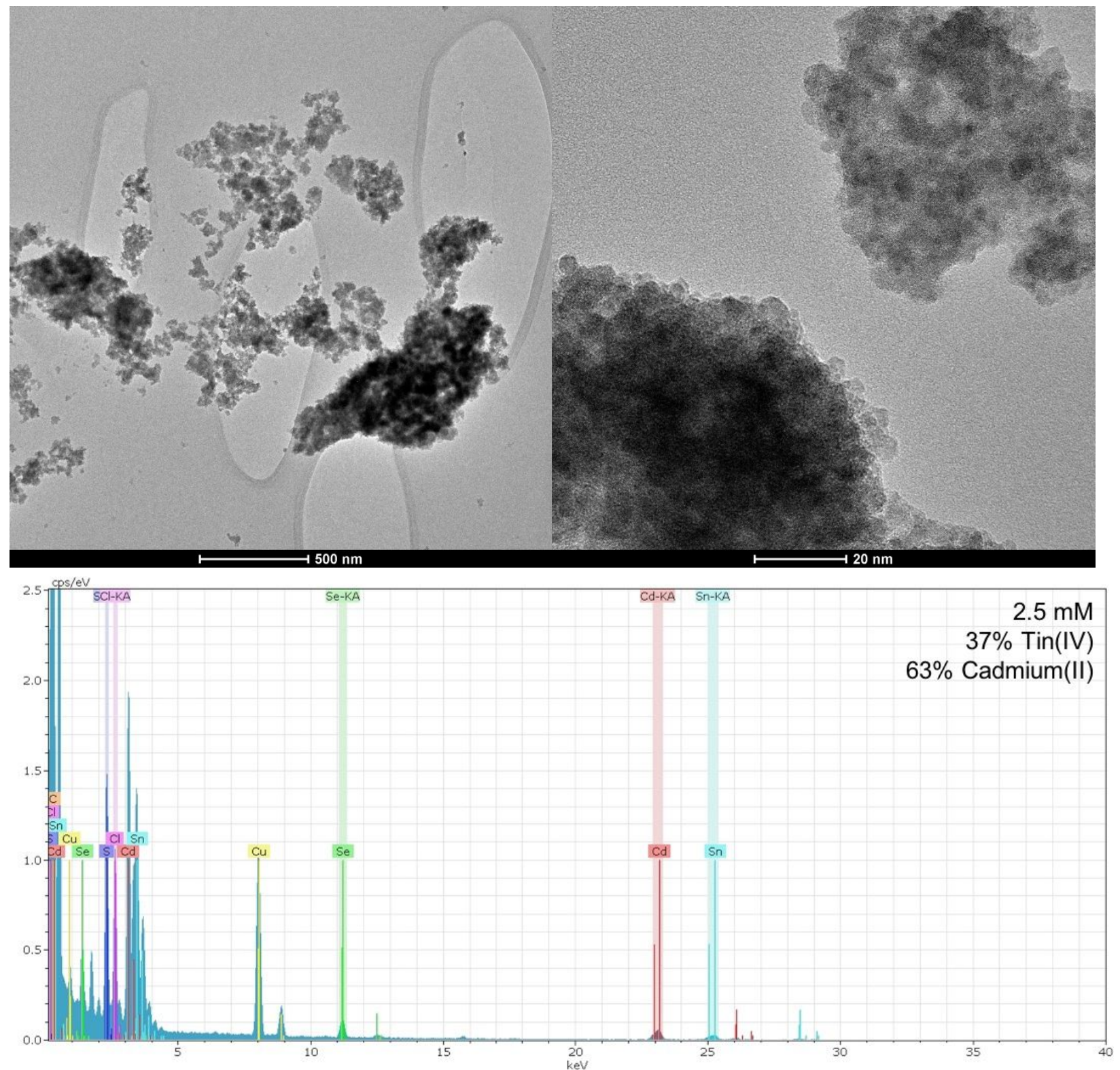

Figure S10. TEM and EDS spectra after cation exchange showing aggregation as well as the presence of each exchange cation after cation exchange.

\section{Tin(IV) cation exchange STEM-EDS quantification}

The ratio of tin(IV) to cadmium(II) increased with increase in concentration of the tin(IV) chloride in ethanol solution. This is shown through quantification of spectra generated from STEM-EDS maps in figure S11 of the resulting ferroelectric nanoparticle aggregates. 

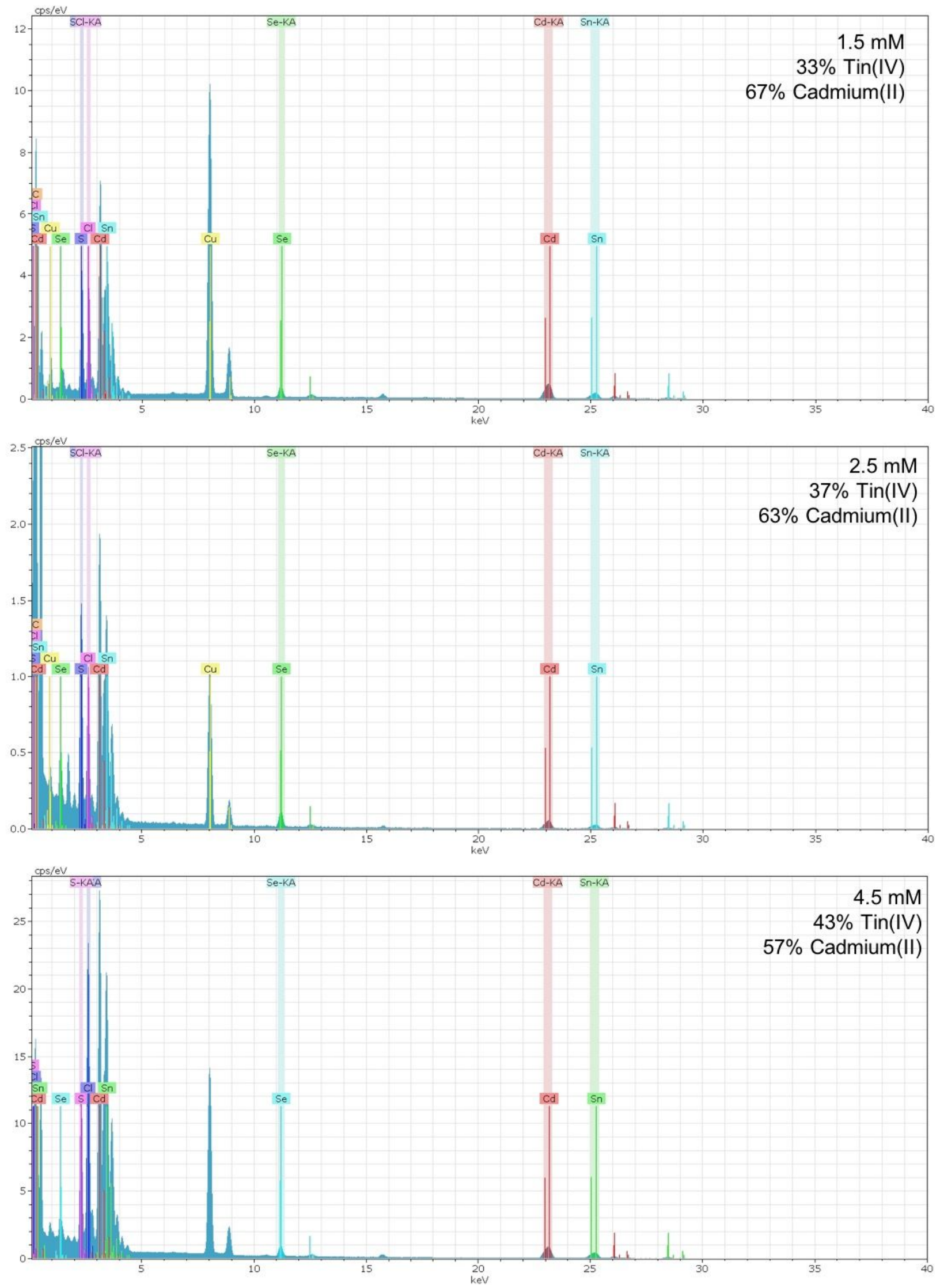

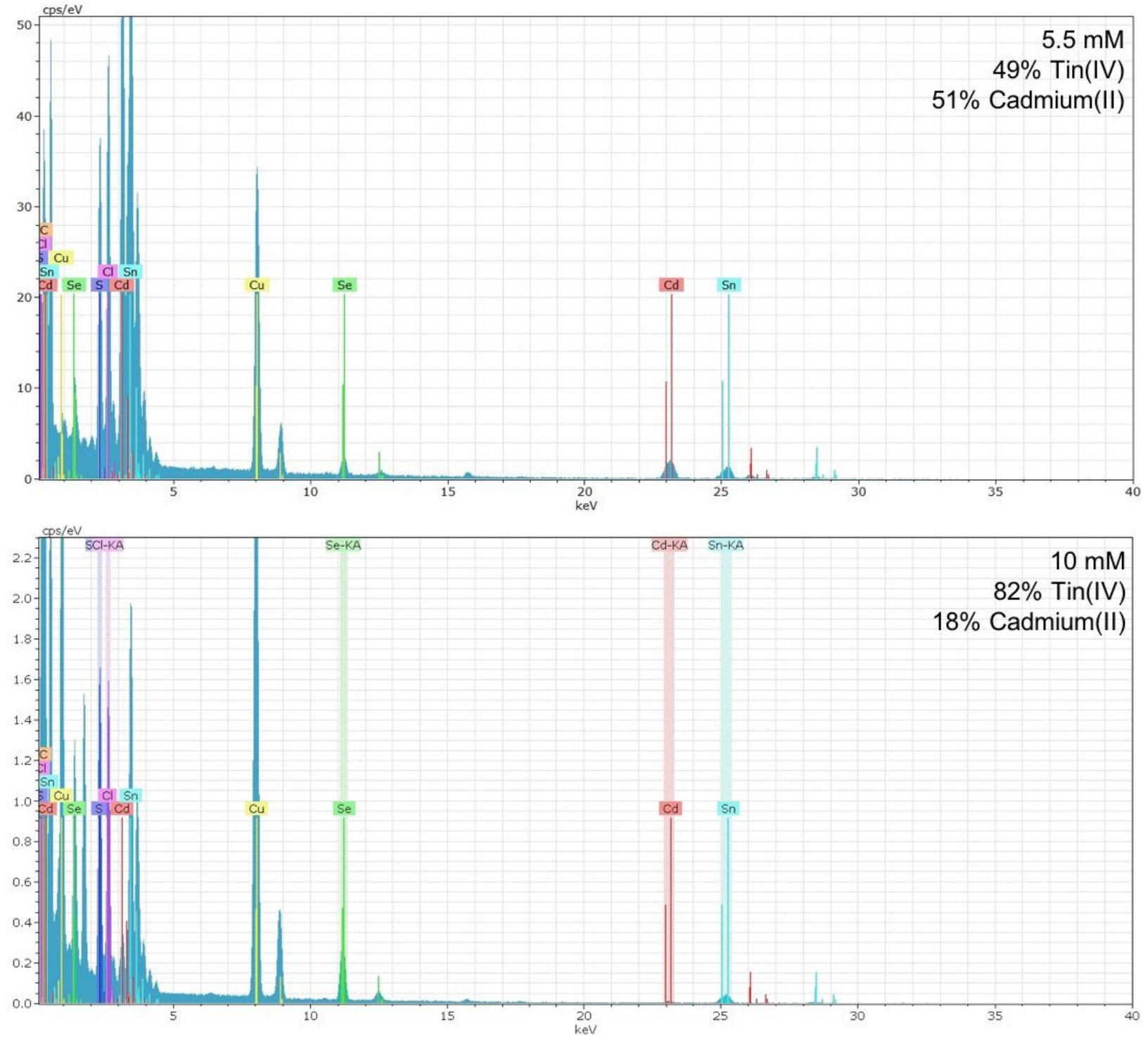

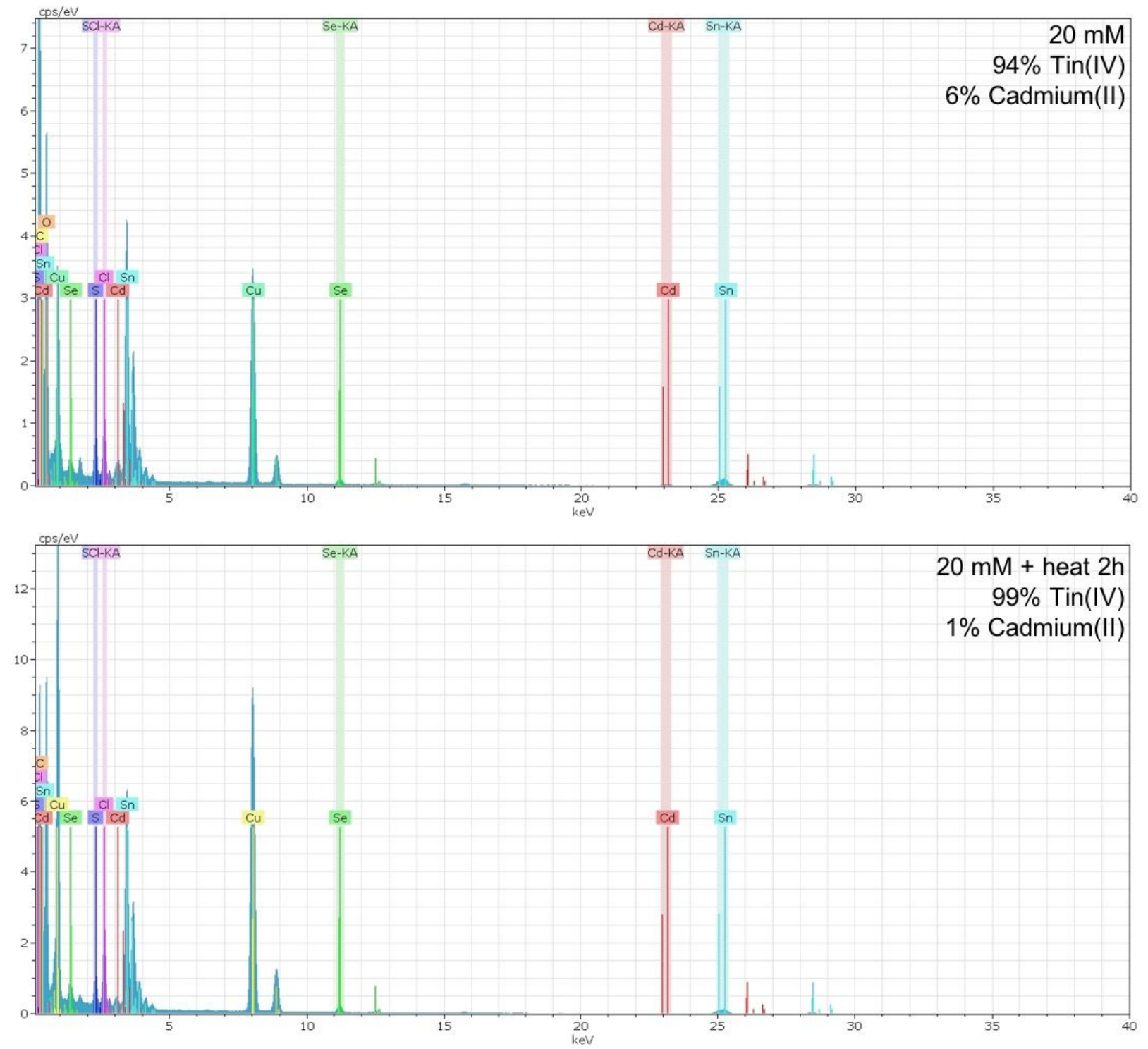

Figure S11. STEM-EDS spectra quantification shows increase the ratio between tin(IV) and cadmium(II) with increase in tin(IV) chloride solution concentration used in the cation exchange reaction as well as heating in the final reaction.

\section{High Concentration byproducts.}

As tin(IV) chloride concentrations reached higher concentrations and as heat was applied, large selenium metal particles began to form, which was apparent in STEM-EDS and XRD analysis. The relatively high concentrations of tin(IV) and increase in temperatures may have caused a REDOX reaction to occur, reducing some tin(IV) to tin(II) and partially oxidizing negatively charged selenium within the nanoparticles to selenium metal. These were removed using a syringe filter and remaining particles were analyzed using XRD shown in figure $\mathrm{S} 13$. Se(0) has not been found to have ferroelectric properties at room temperature. ${ }^{1}$ 


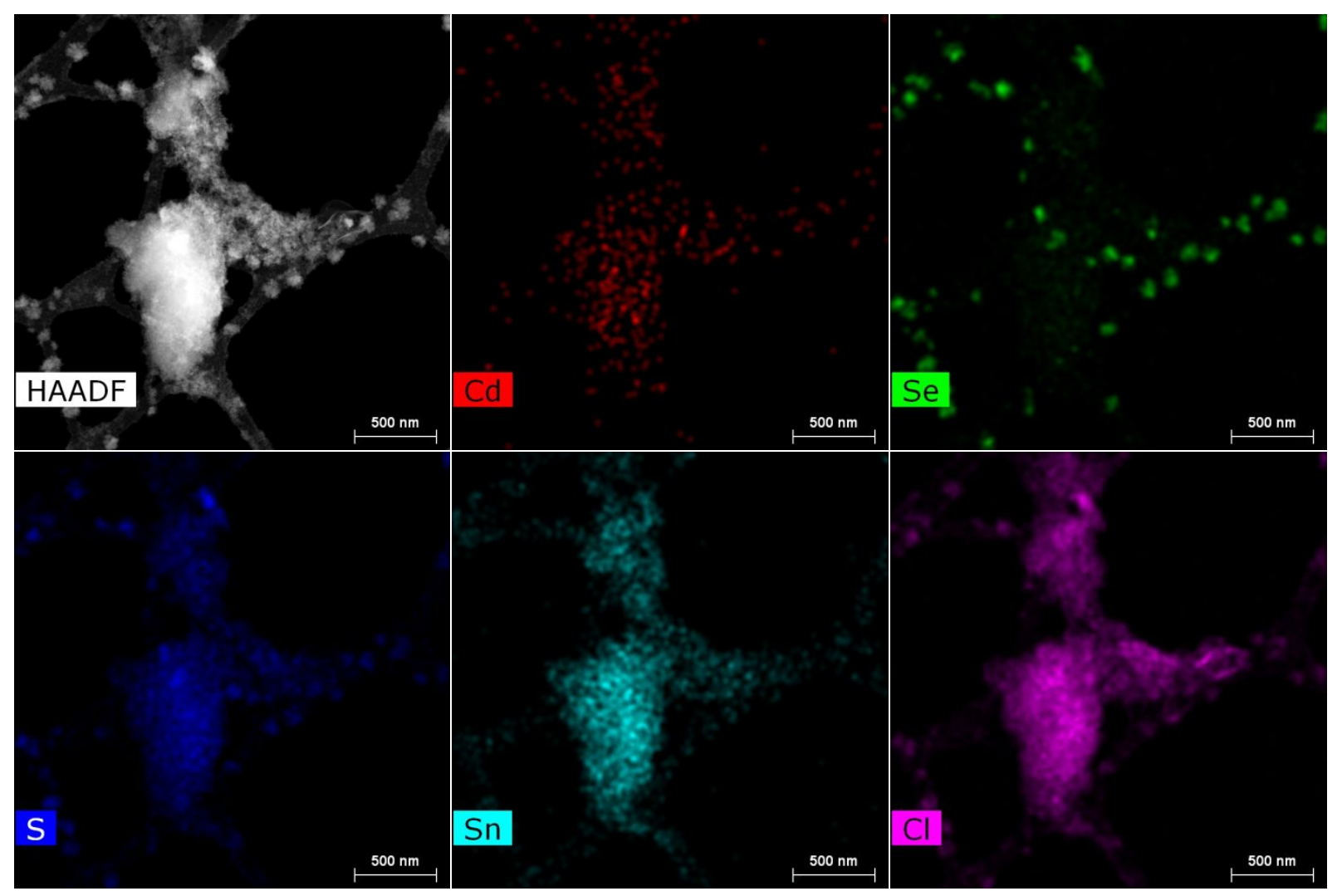

Figure S12. STEM-EDS of high concentration, heated $\mathrm{SnCl}_{4}$ cation exchange reaction, showing the formation of nanoparticle aggregates with high $\mathrm{Sn}^{4+}$ dopant concentrations as well as elemental selenium formation due to possible REDOX reactions due to higher concentrations and increase in temperature. 


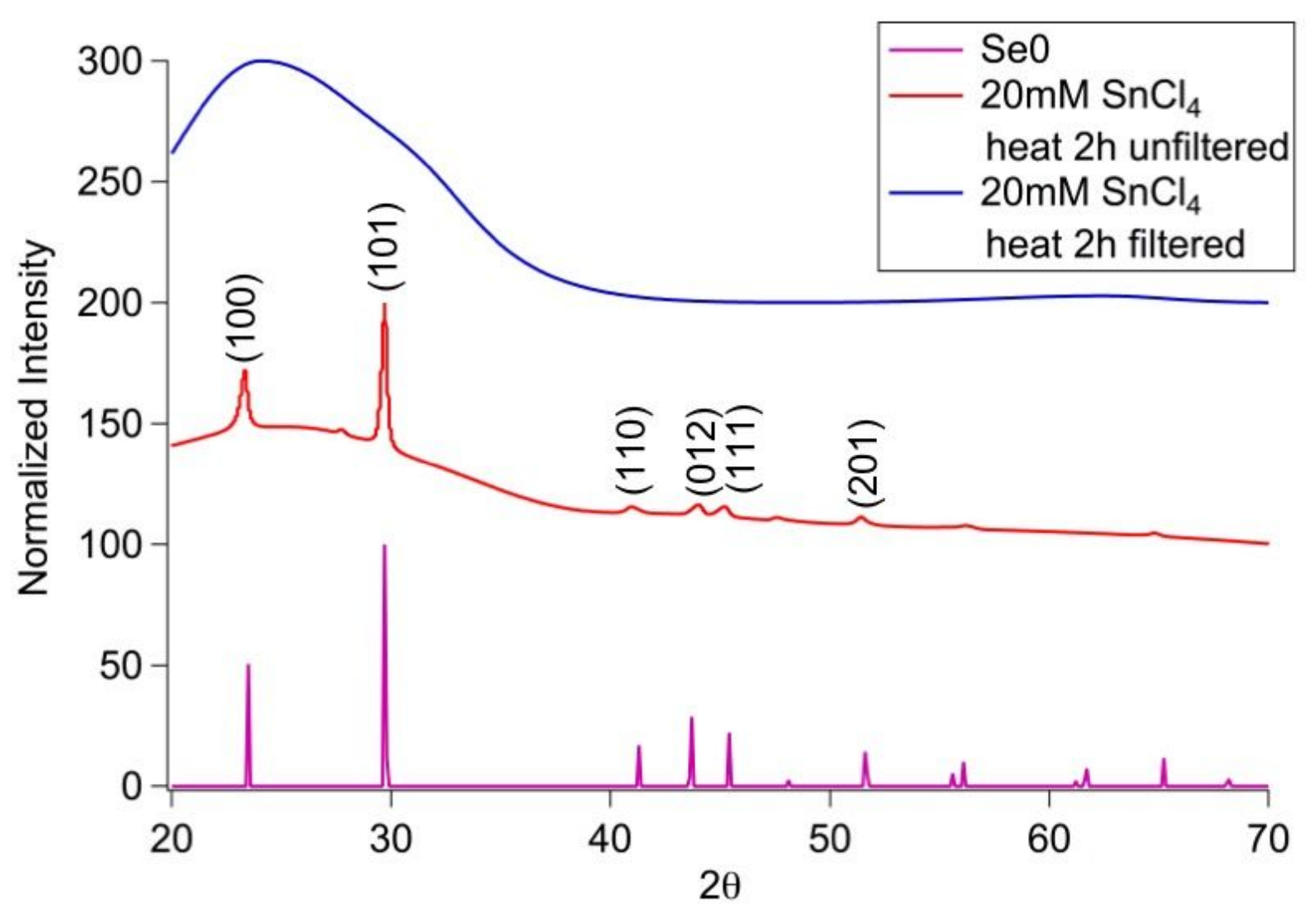

Figure S13. XRD of filtered and unfiltered high concentration, increased temperature CdSSe $\mathrm{SnCl}_{4}$ reaction, showing formation of elemental selenium as well as disordered crystal structure of resulting CdSSe with high $\mathrm{Sn}^{4+}$ dopant concentrations once elemental selenium is removed.

1) Pal, A.; Shirodkar, S. N.; Gohil, S.; Ghosh, S.; Waghmare, U. V.; Ayyub, P. Multiferroic Behavior in Elemental Selenium below $40 \mathrm{~K}$ : Effect of Electronic Topology, Scientific Reports, 2013, 3, 1-7. 